\title{
Internationalization and Digitalization in Engineering Education
}

Strenger, Natascha ${ }^{\mathrm{a}}$; May, Dominik ${ }^{\mathrm{b}}$; Ortelt, Tobias ${ }^{\mathrm{b}}$; Kruse, Daniel ${ }^{\mathrm{a}}$; Frerich, Sulamith C. ${ }^{\text {a }}$; Tekkaya, A. Erman ${ }^{\text {b }}$

${ }^{a}$ Project ELLI, Mechanical Engineering, Ruhr-Universität Bochum, Germany, ${ }^{b}$ Project ELLI, Institut für Umformtechnik und Leichtbau / Center for Higher Education, TU Dortmund University, Germany

\begin{abstract}
Digital, virtual and E-learning elements have increasingly become a part in higher education and, most recently, the high potential of digitalization for processes of strategic internationalization of higher education institutions is coming into focus.
\end{abstract}

The collaborative project of three German universities, ELLI - Excellent Teaching and Learning in Engineering Sciences, is working on strategies for the internationalization and virtualization of engineering education. While these topics used to be different key areas of the project, a combination of both distinguished itself as a potential new working field.

This paper introduces two pilot concepts that were implemented and evaluated at TU Dortmund University and Ruhr-Universität Bochum (RUB) which both aim at the complementation of incoming students' experiences in Germany by digital means. In Dortmund, a transnational online class explores means of preparing degree-mobile engineering students from all over the world for their master's studies in Germany. At RUB, an online course was designed to accompany a summer school research exchange for US-American engineering students in order to prolong their short-term mobility by digital elements.

These pilot projects were well-accepted by students and faculty at both universities and their evaluations between 2014 and 2017 have revealed valuable results for further optimization. This paper presents the results and discusses future potential.

Keywords: Digitalization; Internationalization; E-learning; Virtual learning; Remote Labs 


\section{Introduction}

Since e-learning found its way into higher education institutions, there have been discussions about whether the increasing digitalization might present a threat to the physical nature of universities. Especially when massive open online courses (MOOCs) became a hype around 2012, scepticism arose with regard to the didactical quality of online teaching in higher education (Siemens, 2013). Research on the digitalization of higher education usually concludes that, while e-learning poses a challenge to universities, these institutions have always been facing challenges over the centuries of their existence. Thus, the capability of adapting to a changing society belongs to their inert qualities and interaction between students and university staff and teachers - whether digitally or personally - will certainly remain a crucial educational experience for students (Amirault 2012).

Institutions such as the German Academic Exchange Service (DAAD) have long since recognized the high potential of digital and virtual elements for the internationalization of the German higher education system (DAAD 2014). As several efforts on different levels show, digitalization can play a crucial role for the internationalization of higher education institutions on an organizational level and of education practice on a pedagogical level. Just as the final report of the working group "Internationalization \& Marketing Strategies" in the German Forum for Higher Education in the Digital Age claims: "Digitalization opens up new opportunities for the higher education institutions' on-going internationalization. [...] In the context of educational practice the potentials lie in increasing the mobility of German students and in new ways for internationalizing the curricula."(Hochschulforum Digitalisierung, 2016). Dr. Dorothea Rüland, DAAD general secretary and chair of the group, concludes: "The widespread media penetration of higher education is already in full swing. The age of digital learning and teaching scenarios is giving rise to new value chains for HEIs - its global scope is being expanded, opening up opportunities for advancing the strategic internationalization of German HEIs. In this regard, internationalization is not an end in itself, but rather proves to be a central factor for increasing the quality of research and teaching" (Rüland, 2017). The working group sees key potentials in preparing students online for future stays in abroad countries and in building international digital learning groups for putting virtual mobility into practice.

Project ELLI aims at improving the conditions of teaching and learning in engineering education. The cooperative project of three German universities started off in 2011, funded within the Teaching Quality Pact by the German Federal Government and States. To develop innovative teaching and learning concepts for tertiary education, engineering chairs are working together with institutions for higher education didactics. Based on the project's success during its first five-year term, a subsequent funding was granted for 2016 until 2020. In a cooperation between two of the project's four key areas - Virtual Learning 
Environments and Remote Laboratories and Globalization, two pilot concepts were realized between 2014 and 2017 which combine international teaching formats with digital elements. The following sections will introduce both concepts and the experiences of project coordinators.

\section{Preparing students for international mobility}

\subsection{Using live online classes and remote labs for international engineering education}

At TU Dortmund University, an online course was given to international students coming to Germany in advance of their stay. This course has been meant for preparing them for their future studies of an on-campus master program and at the same time exploring the potentials of live online classes with the help of online conferencing tools and remote labs. From 2014 on the course has been taught as a 4-weeks online seminar and further developed in 3 editions (in summer each year) to over 70 engineering students from over 25 different countries; such as Brazil, Mexico, Nigeria, Egypt, Iran, India, Nepal, Russia or even South Korea. In order to prepare the students for their master program in Germany and based on our lessons learned from recent years, we decided to develop a special online course, which is delivered before the students leave their home country for their stay in Germany.

The course and its concept so far have been explained in detail in several publications (see e. g. May \& Tekkaya 2016 or May et.al. 2016). In the following we will outline the main issues of this course in order to put it into the greater context of internationalization in the light of digitalization and the context presented in the second example later on.

As explained above the course is fully taught online with live-online meetings and the students are, at the moment of course delivery, spread all over the world, which makes it necessary to put a special focus on time zone differences. We solved this problem each year in given the course twice, one time for the more western situated countries (from brazil to Iran) and one time for the far eastern countries (like India and China). Even if this leads to a decrease in terms of cultural diversity we did not see any alternatives if we want to get into synchronous interaction with the students. For in-class interaction we are making use of Adobe Connect, which is a tool for online conferencing and, hence, can be used for class interaction, too. Using this tool we were able to design online classes very similar on-site classes. Hence, we used the online tool for lecturing, group interaction, and group presentations. For these presentations smaller student groups had to work apart from the live class meetings on several topics and prepare presentations. The topics to present on were chosen so that intercultural discussions in the smaller groups were necessary in order to share and compare different opinions cultural viewpoints. For example the students are 
discussing different mobility concept for mega cities from technical, cultural and organizational perspectives. Furthermore they are asked to consider if the different concepts found all over the world would fit in their home countries' context or not.

Furthermore, and this is an unique feature of that online course, we are making use of an online remote experimentation equipment developed and put into practice here at the engineering faculty at TU Dortmund University. The remote laboratory offers the occasion to perform tensile tests, a core experiment in manufacturing technology, from a distance. The physical existing experimentation equipment can be accessed online and results are displayed in a web-based graphical user interface. Using the lab students can access the experiment and analyze the gained data from virtually every place in the world. We used the system in context with the displayed course in order to build up transnational distributed working groups and letting them work in teams with the equipment. For us this is a perfect opportunity to give the students the occasion to work in an international context, share different approaches in experimentation practice among each other and do real-life engineering work in an online environment.

Summing up, the 4 -weeks online course is split into three main parts, each focusing on different main aspects. In each week we have two live online meetings with homework to be done in-between. In the first part, the local and cultural orientation, the students are introduced to the local culture of Germany and the area around Dortmund. Furthermore we are making first steps in reflecting the own cultural background in context with engineering practice, so that the students can compare these cultures later on in that course. In the second part, the global orientation, the students are asked to discuss technology with their own cultural background in mind and compare their viewpoints. Therefore they are working in culturally mixed teams and discuss technical, organizational and cultural aspects of the above mentioned mobility concepts. The last part, the technical orientation, is dominated by a car-body design task. For this task they perform the experiment, again in mixed groups, and use the experiments' results for designing a defined part of a car body.

\subsection{Benefits of preparational online courses and remote labs}

Little time after course completion, the students are coming to Germany. Apart from the advantages that they were working online in international teams and that they already know their destination more in detail, another benefit of such a preparational course is that the students already know each other. Whereas we experienced in former times that especially in an international study programs students are tending to build mono-cultural peer groups we received the feedback with this online course that the students now are working more likely together in mixed groups, even during there stay in Germany. Another positive aspect mentioned by the students is the opportunity to get to know their future destination in advance and prepare them for a cultural clash. From our perspective as engineering teachers 
the opportunity remote labs open up for international education are tremendous. So far online courses had the difficulty that hands-on engineering work could not be done in such online context. Even if it always has been possible to work on engineering tasks even in distributed groups (for example with the help of simulations) it now makes a significant difference using physically existing equipment and knowing that real experiments are part of the students. This is what the students, asked for their favorite activity during the course, mentioned, too. They were both impressed and motivated by the fact that they were using the very same equipment they would be using for laboratory courses during their stay at TU Dortmund University. Even if there remains a lot of research to be done in terms of effectiveness and advantages for the learning process of remote labs in comparison to onsite lab work, we do see high potentials in this technology for the internationalization of engineering education with the help of digitalization.

\section{Enhancing a summer school format by digital elements}

\subsection{Setting up a student exchange in engineering between the US and Germany}

While for German engineering students the US rank as the top destination country for a student exchange (DAAD 2013), their counterparts' interest in coming to Germany for a period of study is not equally great, with other English speaking countries such as Great Britain or New Zealand ranking among their top destinations (Bhandari et al. 2013) To circumvent mobility barriers such as different semester times and language difficulties, summer school formats that are taught in English seem to be what US-American students prefer (Schubert 2013).

Seizing the potential of its process technology laboratories, the faculty of Mechanical Engineering at the Ruhr-Universität Bochum (RUB) established a cooperation with the department of Chemical Engineering at Virginia Tech University in Blacksburg. Since 2015, 15-20 students can be exchanged per year, American undergraduate students coming to $\mathrm{Z}$ for two months during the German summer semester, while German students spend the spring term of the following year in Virginia. At RUB, the American guests take part in the laboratory process technology for 8 weeks and work on individual research projects supervised by a researcher in groups of two. Additionally, they have 60 hours of German classes at the level A1, for most of them come without prior knowledge of German.

The short-term nature of the program seemed to be the best option to circumvent the different semester times of both countries and at RUB, faculty members made a great effort to be able to offer such a compact program with contents in English while most of the regular curriculum is taught in German. However, evaluations of the 2015 pilot run revealed that students - albeit generally appreciating the program - were unsatisfied with 
the little contact they had with German students during their stay here and stated that they would have liked to be better prepared for their stay in Germany. Apparently, a deeper immersion into German academic culture was made difficult by the summer school (shortterm and English speaking) nature of the program. Reacting to those needs, the project ELLI together with the Faculty of Mechanical engineering took to designing an accompanying Webcast and E-learning format which was first tested during the second year of the student exchange, from January to August 2016.

\subsection{Accompanying the summer school with Webcasts and E-learning elements}

With the aim of prolonging the short physical stay for international students who come to Bochum only for two months, the project ELLI decided to enhance the exchange program by digital elements. As a framework for the preparatory course, the project used the ELearning platform Moodle to set up an online course which contains four sections:

The first section gives an Overview of the setup of the exchange program and the accompanying E-learning elements, as well as all persons involved. A Calendar is updated regularly with all important dates regarding classes and research projects, but also excursions and official get-together meetings. As the platform is also intended as a first opportunity for everybody involved to get to know each other before meeting in person, the Contacts field contains short profiles describing students, teachers, and organizers. In cooperation with the university's center for foreign languages (ZFA), a section for Learning German was included, where a preparatory moodle course by the ZFA is linked which provides 12 E-learning units of German A1. Thus, the students could start learning the language at least a little before coming to Germany. The section Research introduces students to the process engineering laboratory environment and respective supervisors of their upcoming research projects. At the same time, supervisors could make use of this platform in order to get to know their future students early on and provide information about their research. Another important aspect was to prepare students early on for their work in the laboratories. Therefore, documents with Safety Instructions for the university's lab facilities were provided that had to be read by students before starting their actual work in the labs. A video was produced especially for this purpose deals with the safety regulations of the institute and shows what to do in emergency situations. For the fourth category, Social, the project produced Video Clips (each about 3 minutes long) which introduce the host university with its campus facilities and the engineering faculties, as well as the surrounding cities and possible free time activities. The videos contain useful practical information such as how to print the semester ticket and get to RUB from the airport by public transportation, or how to use the university and faculty libraries. The moodle course and its contents were introduced to the US-American guest students in two Webcast_Sessions. The sessions, which were run via Adobe Connect, served as a first opportunity for students and organizers to get to know each other and to answer important 
organizational questions. They were accompanied by the supervising university teachers on both sides.

Starting with the webcast sessions in January, the total length of the program could be stretched from a mere two into almost seven months - a prolongation that had a positive effect on students' perception of cultural immersion: While in 2015, they had rated this aspect very low, 2016 participants rated the program "very helpful" in terms of experiencing academic and cultural exchange. As only 8 American students came to Bochum, the high effort put into designing the course by university staff could be regarded as disproportionate. However, the experience shows that with the additional support of a project such as ELLI, a faculty or chair can establish a digital structure (moodle course, videos) that can easily be used again for other exchange programs with only little adjustments. Thus, the pilot run can be seen as a clear benefit to the exchange program and will be be built upon during the years to come.

\section{Conclusions and Outlook}

The experiences of both projects presented in this paper show that - provided they comply with the quality standards of higher education - digital educational offers can support and promote international experience. While they can certainly not replace study periods abroad, they can be used in order to prepare students and teachers for different academic cultures and to give introductions to the languages and subjects of host universities.

With a special focus on engineering education, the possibilities that remote laboratories offer in order to provide hands-on experience for international students even without being on site in Germany became obvious. With regard to the problems student exchange programs often face due to different semester times, it was shown that accompanying digital formats can serve to make a stay in Germany more attractive in terms of cultural immersion for incoming students. A relatively high effort is required in the starting phase of such programs, as digital structures have to be built and their application needs to be tested and internalized by teachers and students. However, once the new digital frameworks have been established, they can increase exchange activities on both sides, at home and abroad, and prepare international students for their studies in Germany.

During its second funding phase, project ELLI will continue to develop measures that combine digitialization and internationalization in engineering education: Transnational education approaches will be enhanced and linked to remote laboratories. The central goal will be to allow for students to strengthen their intercultural competences while working on real engineering and technical problems, in online courses where they can conduct experiments, analyze and interpret their results in international teams. 


\section{References}

Amirault, R.J. (2012). Will E-Learning permanently alter the fundamental educational model of the institution we call "the university"? Trends and Issues in Distance Education: International Perspectives. 2nd Edition, 157-173.

German Academic Exchange Service (DAAD) (ed.) (2013). Wissenschaft weltoffen 2013. Facts and Figures on the International Nature of Studies and Research in Germany. Bielefeld:HIS, DAAD.

German Academic Exchange Service (DAAD) (ed.) (2014). Die Internationalisierung der deutschen Hochschule im Zeichen virtueller Lehr- und Lernszenarien. Bielefeld.

Hochschulforum Digitalisierung (2016). The Digital Turn: Hochschulbildung im digitlaen Zeitalter. Arbeitspapier Nr. 27. Berlin: Hochschulforum Digitalisierung. p.68

May, D., A. E. Tekkaya (2016). Using transnational online learning experiences for building international student working groups and developing intercultural competences. Proceedings of American Society for Engineering Education's 123rd Annual Conference \& Exposition "Jazzed about Engineering Education"; June, 26th29th, 2016; New Orleans, Louisiana, USA; 10.18260/p.27171

May, D., C. Terkowsky, T. R. Ortelt, A. E. Tekkaya (2016). Using and evaluating remote labs in transnational online courses for mechanical engineering students. Proceedings of American Society for Engineering Education's 123rd Annual Conference \& Exposition "Jazzed about Engineering Education"; June, 26th-29th, 2016; New Orleans, Louisiana, USA; 10.18260/p.2713

Raisa Belyavina, Jing Li and Rajika Bhandari (2013). New Frontiers: U.S. Students Pursuing Degrees Abroad: A 2-year analysis of key destinations and fields of study. Institute of International Education (IIE).

Rüland, D. (2017). Marketing strategies for German higher education institutions. Available

online:https://hochschulforumdigitalisierung.de/en/themen/internationalisationmarketing-strategies. last checked on 01/18/2017.

Schubert, Thomas F. Jr. and Jacobitz, Frank G. (2013). Compact International Experiences: Expanding Student International Awareness Through Short-Term Study Abroad Courses With Substantial Engineering Technical Content. Online Journal for Global Engineering Education. Vol. 7: Iss. 1, Article 1. Available online: http://digitalcommons.uri.edu/ojgee/vol7/iss1/1 last checked on 01/30/2017.

Siemens, George (2013). Massive Open Online Courses: Innovation in Education? Open Educational Resources: Innovation, Research and Practice. Vancouver: COL-OECD, $5-15$. 